\title{
Turismo, economía y planificación urbana: una relación compleja
}

\author{
Manuel Ángel Santana Turégano ${ }^{\dagger}$ \\ Universidad de La Laguna (Islas Canarias, España)
}

\begin{abstract}
Resumen: El artículo pretende plantear la necesidad de llevar a cabo un enfoque más social de la actividad económica turística. Muchas de las actividades propiamente económicas del fenómeno turístico se ven influidas en gran medida por regulaciones no económicas como la planificación urbana. El análisis del caso de Maspalomas (Islas Canarias) demuestra que lo que en la propia planificación urbana se concibe como "económico" puede variar, en función de cómo sea definido por los actores. Y que las distintas definiciones de "lo económico" favorecen a unos agentes y perjudican a otros. Por ello, se sugiere que el análisis de estos fenómenos “económicamente relevantes” y “económicamente condicionados” ha de ser incorporado al estudio de la actividad económica turística.
\end{abstract}

Palabras clave: Turismo; Economía; Sociología; Planificación urbana; Desarrollo.

Abstract: The paper puts forward the need to develop a social approach about tourism as an economic activity. Many tourism activities that are considered to be as strictly economic are deeply influenced by non economic phenomena, such as urban planning. The case study of Maspalomas (Canary Islands) shows that what urban planning defines as "economic phenomena" varies depending on how it is defined. And those different definitions about "economy” benefit some agents and hinder others. Therefore, it is suggested that the analysis of "economically relevant” and "economically conditioned" phenomena should be considered when studying tourism economic activity.

Keywords: Tourism; Economics; Sociology; Urban Planning: Development.

\footnotetext{
† Manuel Ángel Santana Turégano es profesor del Departamento de Sociología de la Universidad de La Laguna. Doctor en Sociología por la Universidad Autónoma de Barcelona. E-mail: masantur@ull.es
} 


\section{Introducción}

A la hora de plantearse el estudio del turismo en una determinada región o destino es muy habitual encontrar planteamientos acerca de que el turismo es un campo del saber en el que se entrecruzan distintos conocimientos, lo que hace necesaria la interdisciplinariedad. De hecho, se ha llegado incluso a afirmar que las particularidades del objeto de estudio (el turismo) justifican la aparición de una nueva disciplina científica (Jafari, 2005). En la división entre la Economía y otras Ciencias Sociales, el turismo ha sido visto, en gran medida, como un fenómeno económico, y que por tanto ha de estudiarse con los métodos y técnicas de la "Economía". Pero a la vez, es también un fenómeno social, cultural y territorial, y por tanto ha de estudiarse desde otras perspectivas. Tal como señalan Granovetter y Swedberg (2001: 2 traducción y adaptación propias), lo que determina el tipo de estudio es que algunas materias se consideran como intrínsecamente económicas mientras que otras serían inherentemente sociales (Granovetter y Swedberg, 2001: 2). Así pues, en el caso del turismo esta supuesta "interdisciplinariedad" se transforma en una división entre materias consideradas económicas "per se", del tipo ¿qué es lo que demandan los consumidores turísticos?, que son estudiadas desde el ámbito de la Economía y la Administración de Empresas y materias consideradas como "no económicas" per se, del tipo ¿cómo influye el desarrollo turístico en la cultura de las sociedades receptoras? que son estudiadas desde otras disciplinas.

Aunque apenas ha tenido repercusión en el ámbito del turismo, como reacción a esta situación se han producido esfuerzos que intentan llevar a cabo un enfoque más social de la Economía. Para la Nueva Sociología Económica, la cuestión clave es que muchos problemas económicos, que por definición sea han contemplado como pertenecientes al campo de la economía, se pueden analizar mejor si se tienen en cuenta consideraciones sociológicas. Los principios claves de esta Sociología Económica serían 1) La actividad económica es una forma de acción social 2) la actividad económica está socialmente insertada y 3) las instituciones económicas son construcciones sociales. (Granovetter y Swedberg, 2001: 7). En cualquier caso, si se habla de una "Nueva Sociología Económica" es porque se parte de una "Sociología Económica Clásica", que ha aportado bastante a la definición de la materia de estudio. Y dentro de ésta, la obra de Weber ocupa un lugar central. Siguiendo las aportaciones de Weber, Swedberg plantea que la socio- economía debería incluir no sólo a los fenómenos propiamente económicos sino a los "fenómenos económicamente condicionados" y a los "fenómenos económicamente relevantes". Los "fenómenos económicamente condicionados" serían aquellos que podrían ser explicados parcialmente (si bien remarca que sólo parcialmente) por la influencia de factores económicos. Los "fenómenos económicamente relevantes" serían aquellos que no son económicos por sí mismo pero que influencia los fenómenos económicos", y el ejemplo que es la manera en que el protestantismo ascético ayudó a formar la mentalidad del capitalismo moderno, tal y como se desarrolla en "La ética protestante y el espíritu del capitalismo" (Swedberg, 2001: 83, traducción y adaptación propias). Este planteamiento aporta un enfoque muy interesante al estudio del turismo, pues puede considerarse que muchos de los fenómenos relacionados con el turismo entran en una de estas tres categorías. Así por ejemplo, no hay duda de que los criterios de elección vacacional, aunque no sean estrictamente económicos, se ven sin duda influenciados por una variable típicamente económica como el precio. Por otra parte, la ordenación territorial y las justificaciones que se usan para legitimar o no determinadas actuaciones urbanísticas, que constituyen la base del desarrollo turístico, no son en sí fenómenos económicos pero sí "fenómenos económicamente relevantes", siguiendo esta tipología.

Para el análisis de estos fenómenos "económicos" (en sentido amplio) Weber contrapone dos tipos de economía. Por un lado, aquellas que son estáticas y están orientadas a la renta (rent) y a la riqueza 
(en el sentido de "fortuna", wealth) y aquellas que son dinámicas y están orientadas al beneficio (profit) y al capital. Conjugando esta distinción con otros factores, la "economía capitalista" podría dividirse en tres tipos ideales: "capitalismo racional", "capitalismo político" y "capitalismo comercial tradicional". Él capitalismo tradicional representa un tipo de capitalismo que existe desde hace mucho, y que consiste en formas sistemáticas de comercio e intercambio de dinero. El capitalismo político significa esencialmente la consecución de beneficios a través de contactos políticos o bajo protección política directa, y puede encontrarse tanto en la antigüedad como en el mundo moderno. Por último, el capitalismo racional es lo que se suele llamar "capitalismo de libre mercado". En este caso, el principal actor es la empresa moderna, guiada por un emprendedor y orientada a la explotación de oportunidades de mercado. (Swedberg, 2001: 86, traducción y adaptación propias). El estudio de las "variedades del capitalismo" ha sido uno de los temas centrales de la "Sociología Económica", frecuentemente llamada "Sociología Industrial, del Trabajo o de la Empresa". A partir del estudio seminal de Piore y $\mathrm{Sa}^{-}$ bel (1990) la idea de la existencia de un único modelo de desarrollo socio- empresarial, en último término, de capitalismo, se ha visto superado. Frente al así llamado "modelo de producción fordista" se han contrapuesto otros modelos: la especialización flexible, el toyotismo, los distritos industriales de la tercera Italia, etc. ( ver por ejemplo, Boyer y Freyssenet, 2001). En cuanto al mundo del turismo, si bien se ha escrito bastante sobre "fordismo y postfordismo en el turismo" (sólo a título de referencias: Marchena Gómez, 1994; Ioannides y Debbage, 1997; Donaire, Fraguell y Mundet, 1997; Mazón, 2001; Santana Turégano, 2000) e incluso algo sobre "organización industrial del sector" (Davies, 1999), la literatura se centra en analizar estos modelos como "formas de demanda turística", más que como "modos de capitalismo turístico". Quizá porque se tiende a entender que el turismo es un "epifenómeno", y que lo central de las sociedades capitalistas está en otros tipos de producción. Ahora bien, si tenemos en cuenta que para muchas sociedades del planeta el turismo es una de sus principales producciones, cuando no la principal, resulta crucial investigar acerca de los "modos de capitalismo turístico". Aún es más, un avance en la investigación socioeconómica sobre el turismo implicaría recontextualizar socialmente la actividad económica turística.

Si la economía se define como "el estudio de las actividades relacionadas con la producción y con el intercambio de bienes" (Samuelson y Nordhaus, 1990: 5), parece evidente que una "Economía del turismo" debería tratar (y de hecho ha tratado) cómo se produce un conjunto de servicios turísticos que tienen valor en el mercado (y que de manera muy simplificada podríamos considerar "experiencias turísticas"). Aunque es cierto que el hecho de que unos bienes o servicios tengan o no valor de mercado depende de condicionantes sociales, esto se da también en otras áreas, y por tanto no constituye una particularidad del fenómeno turístico. En definitiva, el estudio económico del turismo tiene que ver sobre todo con la llamada "función de producción", definida como "el nombre técnico que se da a la relación entre la cantidad máxima de producción que puede obtenerse y los factores necesarios para obtenerla" (Samuelson y Nordhaus, 1990: 580). Se supone que cada actor económico trata de "producir eficientemente, es decir, con el menor costo posible. Es decir, siempre intenta obtener el máximo nivel de producción con una cantidad dada de factores, evitando el despilfarro siempre que es posible" (Samuelson y Nordhaus, 1990: 580).

Los "fenómenos económicos" resultan determinados en gran medida por factores sociales que, siguiendo la terminología de Weber, resultan "económicamente relevantes". Así, no sólo la innovación tecnológica determina la función de producción, sino que las regulaciones institucionales determinan en gran medida las opciones posibles. Por ejemplo, en los inicios de la Revolución Industrial no usar niños para el trabajo en las minas podría haber sido un "despilfarro" (siguiendo la terminología anterior) mientras que hoy en día es una opción que sencillamente queda fuera del abanico de 
los posibles. Ahora bien, si llevamos estos conceptos al turismo veremos que éstos resultan en gran medida afectados por la planificación urbanística. De manera que, y ésta es la principal aportación de este trabajo, la planificación urbana debería ser incorporada al estudio socio- económico del turismo. Si intentamos traducir la proposición anterior "obtener el máximo nivel de producción" la "producción turística" podríamos medirla en términos de pernoctaciones o en términos de ingresos por esas pernoctaciones. En cuanto a los "factores de producción", podríamos considerar en el turismo, además del trabajo y la tierra distintos tipos de "capitales". A veces se plantea como una característica propia del sector turístico el que un incremento de las unidades producidas puede provocar una caída del precio que el mercado está dispuesto a pagar por las mismas, lo que podría llevar en último término a una disminución de la producción. Es lo que en Economía se denomina "rendimientos decrecientes de escala (Samuelson y Nordhaus, 1990: 584). Esto no es una particularidad del sector, ya que el turismo depende en gran medida de un factor natural, el paisaje, o mejor dicho, la construcción social en torno a un determinado paisaje. $Y$ es conocido que "muchas actividades productivas que exigen recursos naturales, como el cultivo vitivinícola o la selvicultura, muestran rendimientos decrecientes de escala" (Samuelson y Nordhaus, 1990: 585). La particularidad del turismo sería, si acaso, que siguiendo el modelo del ciclo de vida de las zonas turísticas (Butler, 1980) el desarrollo turístico podría atravesar sucesivas fases en que existen rendimientos crecientes de escala, rendimientos constantes de escala y rendimientos decrecientes de escala (fases de despegue, consolidación y declive, respectivamente, en el modelo de Butler).

\section{El turismo como actividad económica productiva}

La particularidad del turismo tendría que ver más con el hecho de que en la producción eficiente, aquella en que se intenta obtener el máximo nivel de producción con un nivel dado de factores, los factores "dados" son socialmente cons" truidos en un grado mayor que en otros sectores. Dejando de lado la cuestión de los precios y el hecho de que una zona turística menos masificada pueda "venderse" a un precio más elevado que una zona turística menos vulgarizada, en principio parecería lógico pensar que la vía para maximizar la producción turística es elevar el número de "productos turísticos". Y, "ceteris paribus", esto parece pasar, de forma más o menos directa, por el incremento de la densidad edificatoria y de la construcción en vertical. , el número de plantas que puede tener un hotel, que podría considerarse un "factor de producción" y que en cualquier caso determina la productividad de un determinado territorio es una decisión política que se adopta en el marco de la planificación urbanística. Obviamente, no pretendemos afirmar que el turismo sea un objeto de estudio absolutamente excepcional. De hecho, la regulación institucional en actividades como la energía ha tenido siempre mucho peso. Lo único que pretendemos poner de manifiesto es que mientras en otros sectores estas situaciones se han intentado analizar desde enfoques novedosos de socio- economía (como por ejemplo, la Economía Institucionalista) los enfoques predominantes en el sector turístico son exceso "economicistas".

Uno de los aspectos cruciales del hecho de que el turismo como actividad económico productiva se vea influenciado en gran medida por factores sociales es que en función de cómo se defina la situación favorecerá o perjudicará a unos u otros grupos sociales. El modo en que se define socialmente y se sanciona legalmente una determinada "función de producción" implica unos determinados costes de entrada a la actividad, así como una relación fija entre costes de capital y de trabajo. Los cambios en la definición social y legal de la misma pueden implicar, al variar los costes de entrada, que determinados actores que no podían acceder a la misma puedan hacerlo en una nueva situación. En el caso de la planificación urbanística del turismo, favorecer uno u otro tipo de promociones implica que los pequeños capitalistas puedan acceder a la actividad o por el contrario que queden fuera de la 
misma. Dado que quienes se ven perjudicados o favorecidos por una determinada "definición de la situación" constituyen (o pueden constituir) grupos sociales, son capaces de presionar a las instituciones para lograr una definición favorable a sus intereses. La manera en que se fijan las normas es también crucial para determinar el momento en que tienen lugar el inicio de una actividad económica. Pese a que en el largo plazo y a escala global se supone que los factores productivos (fundamentalmente "capital" y "trabajo") acudirán allá donde haya una actividad (en este caso turística) "productiva" o que promete serlo, la movilidad es limitada en el corto plazo. A corto y medio plazo ha de producirse una interrelación entre las "necesidades económicas" y los "imperativos legales".

Por todo ello, la planificación del territorio resulta crucial en el estudio del turismo como actividad económica productiva. Siguiendo la terminología weberiana, la planificación del territorio podría ser considerada como un fenómeno "económicamente relevante". Aunque a partir de aquí haremos referencia básicamente al caso canario, que es el nos sirve de ilustración, muchas de las afirmaciones que aquí se hagan pueden sin duda generalizarse tanto al resto de España como a otros destinos turísticos importantes. En la planificación del territorio intervienen elementos no económicos que acaban configurando los aspectos económicos del turismo. Para que en una localidad se desarrolle la actividad turística es necesario que exista una mínima oferta, al menos alojativa, que acoja a los potenciales turistas. Para que ésta se desarrolle es preciso que la legislación urbanística lo permita. Y para que se desarrolle un plan parcial de urbanización turística es necesario justificar la conveniencia del mismo y que intervengan actores dispuestos a ellos. Desde un punto de vista metafórico se habla muchas veces del mercado turístico. La existencia de éste presupone la existencia de unos "consumidores" turísticos, de unos "productores" y el hecho de que la relación entre éstos se dé básicamente a través de las leyes del mercado. Si bien esta metáfora puede considerarse relativamente acertada para el conjunto del mercado turístico a nivel mundial, no lo es para una localidad o destino en concreto. Y esto obedece a que el hecho de que los "productores" oferten unos u otros productos no depende de las leyes del mercado, sino de otro tipo de leyes en el sentido jurídico del término. En definitiva, pensamos que para un estudio riguroso del turismo como actividad económica productiva es necesario "elucidar entre las fuerzas antagónicas y las relaciones sociales que dan lugar a la aparición y acompañan a determinados modos de desarrollo turístico, siendo estos las específicas combinaciones históricas de tecnologías y relaciones de poder que están en la base de la organización de la producción del turismo en todo contexto histórico- geográfico", tal y como Bianchi (2002: 267 traducción y adaptación propias) planteaba acerca de la Economía Política del turismo.

El urbanismo como "fenómeno económicamente relevante" y "económicamente condicionado"

Siguiendo los planteamientos de Bourdieu (2003) concebiremos la actividad económica como un campo. Por analogía con la terminología deportiva, un campo sería un lugar social, un conjunto de relaciones, un terreno en el que se desarrollan diversos juegos en que los sujetos implicados mantienen luchas para alcanzar diversos objetivos. Ritzer (199350-504) define el campo en Bourdieu como "un tipo de mercado competitivo en el que se emplean y despliegan varios tipos de capital (...). Las posiciones de los agentes dentro del campo dependen de la cantidad y peso relativo del capital que poseen". Lo que está en juego es el envite, es decir, aquello que los sujetos que participan en el campo tratan de conseguir, pero también las reglas mediante las cuales se considera lícito conseguir esos fines, y que por lo tanto pueden facilitar o impedirnos obtener nuestro objetivo ${ }^{2}$. Un envite es tanto un juego en sí, como las reglas de ese juego.

En toda sociedad existen diversos campos, relacionados pero relativamente autónomos entre sí. Entre los diversos campos mencionados por Bourdieu (1994, 
2000, 2003; Ritzer, 1993) están el económico, cultural, social y simbólico. La definición de las mismas puede ser comprendida de forma más o menos intuitiva, de hecho el propio Bourdieu afirma, respecto al capital social, que "se puede ofrecer una idea intuitiva del mismo diciendo que es lo que en el lenguaje cotidiano se denomina "las relaciones". Sin embargo, lo fundamental en la perspectiva de Bourdieu es que todas las formas de capital se acumulan, transmiten, reproducen y tienen distintas tasas de conversión entre sí. Esto es, el capital económico puede convertirse, en función de unas "tasas de conversión determinada" en capital social, y viceversa. (Bourdieu, 2000: 56-57).

El turismo, como actividad económica productiva, y específicamente la planificación urbanística en torno a la misma, son un "campo" privilegiado para la conversión de los distintos tipos de capital. Para llevar a cabo una promoción turística no basta con tener dinero para invertir (capital económico). Es necesario tener también "capital social" que nos informe de dónde poder invertirlo, qué terrenos van a modificar su cualificación y demás, pues la información de que disponen los agentes económicos no es nunca perfecta, y menos aún en el campo de la planificación urbana. Pero es necesario además tener un "capital cultural", que permita no sólo comprender los complicados entresijos técnicos de la planificación urbanística, sino cómo una cultura distinta puede ver como un atractivo o recurso turístico lo que para otros no es más que un espacio improductivo ${ }^{3}$. Por último, es necesario también disponer de un "capital simbólico" que es lo que en último término va a permitir la justificación o legitimación de un desarrollo urbanístico.

Es precisamente esta última forma de capital, el "capital simbólico" en la que centraremos nuestro análisis. Y para analizar cómo las distintas formas de capital (económico, cultural o social y simbólico) se interrelacionan para lograr el desarrollo turístico es necesario analizar el proceso urbanístico previo al desarrollo turístico. La construcción de una urbanización turística, en definitiva, la puesta en marcha del turismo como actividad económica productiva, implica un largo proceso ad- ministrativo que pasa por distintas fases. El caso que aquí se ha analizado es el desarrollo de la zona hoy conocida como "Maspalomas- Costa Canaria", en el municipio de San Bartolomé de Tirajana (Gran Canaria), pero procesos similares se dan en el resto de Canarias, España y posiblemente en otras muchas zonas turísticas. El primer paso para el desarrollo turístico es que exista un cambio en la clasificación del territorio que permita la urbanización y la construcción de infraestructuras turísticas. Para el caso de Maspalomas, entre 1964 y 1991 se han aprobado 17 proyectos, entre proyectos de urbanización, y planes parciales ${ }^{4}$, según consta en los archivos de la Consejería de Política Territorial y Medio Ambiente en Las Palmas de Gran Canaria, organismo encargado en la actualidad de la gestión del territorio en Canarias (para más detalles, ver Santana Turégano, 2003: 141). La capacidad prevista en estos planes era de 72.747 plazas alojativas, siendo la capacidad actual de la localidad de cerca de 100.000 plazas. Todos estos planes han de comenzar con una "justificación", en que se argumenta la conveniencia de dedicar el territorio a la actividad turística. La menor o mayor necesidad de argumentación dependerá en gran medida de los usos anteriores del territorio y de los agentes implicados en los mismos. Es decir, si un territorio que se quiere dedicar al turismo tiene previamente un uso agrícola importante, y los agentes implicados en el mismo disponen de importantes capitales (económicos, sociales, culturales o simbólicos), será necesaria una argumentación más fuerte a favor del desarrollo turístico. Por el contrario, cuando el uso que se le da a un territorio previamente al desarrollo turístico es menor, la necesidad de argumentación puede ser también menor.

Del análisis de los planes de urbanización, así como de las alegaciones presentadas a las Normas Subsidiarias del $\mathrm{mu}^{-}$ nicipio (elaboradas en 1986) se deduce que los argumentos utilizados para justificar el desarrollo turístico son fundamentalmente de dos tipos ${ }^{5}$, que podríamos denominar "naturalistas" y "economicistas". Los argumentos de carácter "naturalista" hacen referencia a la idea de que 
dadas las características naturales de un determinado territorio (horas de sol, temperatura, cercanía al mar, etc.), es "natural" dedicarlo a la actividad turística. En la Justificación que se hace del Proyecto de Urbanización de la zona "El Oasis", en Octubre de 1963, el primero llevado a cabo en el Sur de Gran Canaria, el promotor afirma que los motivos que justifican el desarrollo son: "1) El auge que, en los últimos años ha adquirido el Turismo en la isla de Gran Canaria, centro eminentemente internacional y paso forzoso de la navegación marítima y aérea que une continentes. 2) El clima excepcionalmente agradable que impera en la Isla, de "eterna primavera", y principalmente en la zona donde se proyecta la urbanización, en que, por su situación geográfica y cielo completamente despejado es posible la práctica de toda clase de deportes y actividades al aire libre. 3) La variedad del litoral, la sucesión de interminables contrastes y paisajes; la alternativa de costas bravas; bahías abiertas; ensenadas y playas; el incomparable atractivo del desierto, y sus dunas; la misteriosa potencia vitalizadora del suelo sureño (...)6.

La visión del desarrollo turístico como un hecho "natural" e inevitable lleva a olvidar que el proceso de urbanización es siempre un proceso social, y se llega a plantear que es el propio suelo el que "per se" tiene vocación (como si fuera un sujeto) de ser convertido en urbanización turística. Un ejemplo de esto es la alegación presentada por un particular, que quiere que su terreno se recalifique como apto para la urbanización, a las Normas Subsidiarias de 1986: "Nuestros terrenos, topográficamente, son idóneos para ser calificados como suelo apto para la urbanización residencial turística (...) lo anterior no deriva de caprichosas y subjetivas apreciaciones, sino de la realidad objetiva y de la vocación propia que todo suelo tiene "per se" desde el punto de vista urbanístico 7 ".

En cuanto a los argumentos de carácter economicista, justifican el desarrollo turístico en base al beneficio económico que la actividad traerá para la localidad. Es decir, a partir de unos conocimientos y un lenguaje basado en versiones un tanto simplificadas de la Economía, se argu- menta que el turismo constituye una especie de "innovación tecnológica" en el uso del territorio que permite incrementar la productividad del mismo. De forma que unos terrenos que dedicados a la agricultura apenas producían riqueza, si se dedicaran al turismo producirían mucha $\mathrm{ri}^{-}$ queza, lo que redundaría en el bienestar de la comunidad local. Y el debate acerca de si debe darse o no desarrollo turístico se plantea en términos económicos (muy simplificados, sin duda) de si el turismo contribuirá o no al incremento de la riqueza. Así por ejemplo, en las alegaciones a las Normas Subsidiarias de 1986 se realizan las siguientes afirmaciones: "Nos parece imprescindible contribuir, por diversos medios, no solo a la creación de un Centro que constituya un factor adicional de creación de riqueza y puestos de trabajo, singularmente en momentos, como los presentes, en que tanto se requiere, sino en dar belleza al lugar, incorporado al mismo algo que, como todas las promociones del grupo" $X X X$ ", se caracteriza por su incuestionable calidad ${ }^{\prime}$ Otro particular afirma: "El nuevo destino que se pretende para la Parcela $B$ aportará $a$ la zona turística una cantidad de beneficios que deberán ser tenidos en cuenta, a saber a) Beneficios Públicos (....) b) Beneficios Económico- Sociales indudables, puesto que la creación de un complejo turístico de tal calidad lleva aparejada la captación de un turismo de alto poder adquisitivo, amén de inversiones en divisas que se radican en nuestra región, lo que se traduce en nuevos puestos de trabajo y mayor movimiento económico $10^{-}$ cal9".

No es sólo que los argumentos se lleven al terreno de "lo económico", sino a una determinada visión de la Economía que pretende olvidar que la "economía" no es una ciencia natural y que muchas cuestiones están sujetas a discusión. Dejando de lado las discusiones acerca de los términos "renta" y "riqueza", las propuestas incluyen unas "recetas" para mejorar el turismo en la zona (captar turismo de alto poder adquisitivo) que se dan por válidas sin mayores cuestionamientos. En esta misma línea, las propuestas incluyen a veces no sólo el tipo de turismo que se debería captar, sino incluso la organiza- 
ción que debería tener la industria turística: "No pasarán muchos años para que otra vez nos veamos en una situación similar a la presente carencia de suelo que tanto daño ha provocado, por el desvío de inversiones turísticas hacia otras latitudes. Téngase presente también que la manera más efectiva de captar mayores cuotas en el mercado turístico pasa necesariamente por facilitar los procesos inversores por parte de las grandes compañías que controlan el mercado, puesto que realizadas las inversiones serán sus titulares los primeros interesados en propiciar los flujos turísticos necesarios para garantizar la rentabilidad de sus explotaciones. 10 ".

Como ya dijimos, la planificación urbanística del territorio para el turismo es un "fenómeno económicamente relevante", porque sin ser un fenómeno económicamente en sí influye en la actividad económica del turismo. Pero como acabamos de ver, puede considerarse también un "fenómeno económicamente condicionado". En la medida en que consiga imponerse una determinada visión de política económica, como por ejemplo, que para el desarrollo turístico hay que facilitar la entrada de las cadenas internacionales, esta definición "económica" acaba influyendo en la decisión acerca de qué tipo de urbanizaciones se construyen, que se toma mediante sistemas institucionales (regulación legal) y no mediante sistemas económicos de mercado. De forma que es plausible que en muchos casos se acabe produciendo lo que en Sociología se conoce como "la profecía que se cumple a sí misma" (Tezanos, 1995). Lo que se define como real acaba siendo real en sus consecuencias. Si la idea de que el turismo (o un determinado tipo te turismo) es la única vía para el desarrollo de una región acaba teniendo plasmación en la normativa, se tomarán medidas para fomentar la actividad, en detrimento de otras. De manera que lo que inicialmente era una idea acaba siendo una realidad. Por ejemplo, las Directrices de Ordenación del Territorio y del Turismo (Gobierno de Canarias, 2002) parten del supuesto de que para mejorar la competitividad del sector en Canarias es necesario reconvertir gran parte de la planta extrahotelera en hotelera. Este supuesto se ha plasmado en normativas que, por ejemplo, facilitan la renovación de los hoteles con descuentos fiscales que resultan muy difíciles o imposibles de lograr para los establecimientos extrahoteleros. Según los datos oficiales (Gobierno de Canarias, 2006, elaboración propia), entre 1996 y 2005 las plazas hoteleras habrían pasado de representar un 26 a un $32 \%$ del total de plazas alojativas de Gran Canaria, cifras que para el caso del municipio que nos ocupa, San Bartolomé de Tirajana, son de 23 y 29\%. ¿Son estas cifras la muestra de la actuación de los "imperativos económicos" de un "mercado" que cada vez se decanta más por los establecimientos hoteleros? $\measuredangle O$ son por el contrario el resultado de una normativa que favorece la construcción de unos establecimientos en detrimento de otros en base a las "supuestas demandas de los mercados"? Esta pregunta es de difícil respuesta y no es aquí nuestro objetivo responderla, pero en cualquier caso pone de manifiesta la intrincada relación entre fenómenos económicos, económicamente relevantes y económicamente condicionados, al menos en el sector turístico que nos ocupa.

\section{La planificación urbanística del turismo como un envite económico.}

Del análisis de los documentos de planeamiento la conclusión que podemos extraer es que la planificación urbanística del turismo puede ser considerada, al menos en gran parte, como un campo económico, ya que aquello que está en juego (el envite) tiene que ver con la "economía". Aunque sin duda intervienen otros elementos, como la conservación de elementos patrimoniales o identitarios o la mejora del bienestar de las poblaciones residentes, la planificación urbanística del turismo se orienta sobre todo hacia la ordenación del turismo como actividad económica (lo que acabaría repercutiendo en último término en el bienestar de las poblaciones residentes). Y lo que resulta crucial es cómo se define aquello que está en juego.

El objetivo del envite (juego) que tiene lugar en este campo podemos definirlo, de manera provisional, como "mejorar la 
Economía de la zona". Como en todo envite en sentido bourdeiniano, lo que está en juego no es sólo el resultado final sino las reglas que rigen el juego y cómo se define el resultado final. En función de que esto se haga de una u otra manera los distintos agentes mejorarán o empeorarán sus posiciones. Y siendo conscientes de ello, los agentes intentan intervenir en la definición. En un sentido económico moderno la renta ha sido definida como "la cantidad total de dinero que recibe una persona o una economía doméstica en un determinado período de tiempo (normalmente un año" (Samuelson y Nordhaus: 1990:744). Teniendo en cuenta esta definición, el "mejorar la Economía de la zona" puede entenderse básicamente de dos formas, que no siempre coinciden: o bien se trata de incrementar la riqueza (renta) total producida en una zona, incorporando más factores (tierra, capital, trabajo) o bien se trata de mejorar la productividad de una economía, logrando un aumento en la producción que se consigue añadiendo una unidad más de un factor.

Un análisis "económico" del proceso de desarrollo del caso que usamos como ilustración, que seguramente podría generalizarse a otras zonas turísticas de Canarias, España y el resto del mundo permite ver que lo que ha sucedido es que en las primeras fases del desarrollo turístico éste se ha centrado más en la elevación de la renta total que de la productividad. En un territorio anteriormente poco poblado y con escasa disponibilidad de capital se han instalado empresas y trabajadores que han permitido, valga la generalización que muchas veces se utiliza, que un entorno prácticamente desértico hace cuarenta años sea hoy el "motor económico" de la isla de Gran Canaria. En fases posteriores del desarrollo turístico, en las que la ocupación del territorio es mayor, empieza a hablarse de incremento de la productividad y no del volumen de la actividad turística. Y es éste el argumento "económico" que está detrás de la mayoría de discursos acerca del llamado "turismo de calidad". Tal y como lo expresaba en 1997 el entonces Concejal de Turismo de San Bartolomé de Tirajana, la idea es que "Hay una cosa que está clara, y es que nosotros tenemos que ir a un turismo de calidad, porque con menor cantidad vamos a obtener menos ingresos." 11

El que los poderes públicos definan el objetivo de la "economía" como el "incremento de la productividad" tiene por lo general una plasmación en las normativas (municipales o no) que acaban determinando las "reglas del juego" de la economía, lo cual favorece a unos agentes y perjudica a otros. Y lo mismo sucede si el objetivo se define e términos de "incremento de la renta". Desde el punto de vista del incremento de la productividad, las grandes torres de apartamentos y hoteles que se levantan en buena parte del Mediterráneo serían "lógicas": permiten maximizar el número de estancias o pernoctaciones por metro cuadrado de solar cercano a la costa. Por el contrario, el "hallazgo" que motivó este trabajo es que en el análisis del caso de Maspalomas se encontraron normativas urbanísticas y modificaciones de las normativas urbanísticas que podrían ser consideradas, desde este punto de vista, antiproductivas. En lugar de pretender incrementar la edificabilidad en número de plantas de los terrenos a urbanizar turísticamente se daban acciones que pretendían justamente lo contrario, reducirla ${ }^{12}$. En definitiva, en función de la fase del desarrollo turístico y de los agentes que intervienen en la normativa puede optar por 1) maximizar la renta, aún a costa de una productividad no tan elevada 2) maximizar renta y productividad o 3) maximizar la productividad. Y la hipótesis de trabajo que queremos plantear es que en función del equilibrio de poderes entre los agentes que se ven beneficiados por una $u$ otra definición dependerá el resultado final del "envite".

El modelo urbanístico- turístico de Maspalomas presenta una particularidad en el contexto español, que es el predominio de la oferta extrahotelera sobre la hotelera. Este hecho se debe (Santana Turégano, 2003) al sistema de "venta sobre planos", predominante en la construcción de una gran parte de la infraestructura alojativa, y que consiste aproximadamente en lo siguiente. Un pequeño promotor, normalmente de origen local, adquiere unos terrenos en la zona de Maspalomas susceptibles de uso turístico. 
$\mathrm{Al}$ carecer del capital necesario para construir un hotel, edificio de apartamentos o complejo de bungalows, recurre al apoyo de los Tour operadores y de los pequeños inversores (en su mayoría de origen local). Los tour operadores, que preveían una demanda importante de turistas hacia la zona, apostaban por la misma realizando "contratos en garantía", mediante los cuales garantizaban unos pagos mensuales por el alquiler de unos apartamentos que en muchos casos aún no habían sido construidos. Los pequeños inversores, por su parte, entregaban una cantidad de dinero, relativamente reducida, como entrada por el pago de los apartamentos o bungalows, y financiaban el resto mediante una hipoteca, con la expectativa de que los pagos de los tour operador fueran iguales o ligeramente superiores a las cuotas mensuales de la hipoteca, de forma que al cabo de unos años tendría un apartamento que "se había ido pagando solo". Como resultado de este sistema, se estima que para el verano de 2002 un $75 \%$ de la oferta extrahotelera estaba en manos de pequeños propietarios, un $75 \%$ de los cuales eran de origen local (Santana Turégano, 2005). Por tanto, el predominio de este sistema es el que permite comprender las actuaciones sobre las normativas, anteriormente mencionadas, que reducían la posibilidad de construir en altura, y que podrían considerarse como "antiproductivas" desde un punto de vista económico. Un análisis de la identidad de quienes presentaban alegaciones durante el proceso de definición de las normativas urbanísticas en Maspalomas permite comprender que una normativa de este tipo favorece a unos agentes económicos y perjudica a otros. Por comparación a un sistema basado en la construcción de hoteles, este sistema permitió rebajar los costes de entrada a la actividad turística (en concreto, a la actividad alojativa), permitiendo acceder a la misma a agentes que no podrían haberlo hecho en otros casos. Durante muchos años, el bajo coste de entrada en la actividad ha propiciado la estructuración de la oferta en torno a una situación de competencia, y dificultado el establecimiento de monopolios $u$ oligopolios, que se hubieran desarrollado probablemente si unos costes más eleva- dos de entrada en la actividad hubieran disminuido el número de agentes capaces de acceder a la misma. De hecho, resulta significativo que no es hasta mediados de la década de 1980 cuando las grandes cadenas hoteleras vacacionales, entran en la oferta alojativa de Maspalomas, en un momento en que con una capacidad cercana a las 100.000 plazas alojativas la localidad es ya un destino turístico de primer orden.

Una vez más avanzado el proceso de construcción de las infraestructuras turísticas, la situación anteriormente mencionada en que la normativa urbanística de alguna manera favorecía la entrada de pequeños capitalistas en el negocio turístico se vio por completo revertida. De hecho, en los inicios del siglo XXI la "moratoria turística" del Gobierno de Canarias (2001), impedía la construcción de establecimientos alojativos salvo para los hoteles de cinco estrellas o aquellos de cuatro que fueran asociados a instalaciones de ocio como puertos deportivos, campos de golf o parques temáticos. Si tenemos en cuenta la inversión necesaria para construir estas infraestructuras vemos que la nueva normativa dificulta enormemente la inversión a los pequeños inversores y deja el terreno prácticamente libre para los grandes inversores. Seguramente existe relación entre este hecho y la disminución del peso del alojamiento extrahotelero sobre el total de la oferta ya comentada anteriormente. Esto se relaciona también con la configuración cada vez más oligopolística en que unas pocas cadenas controlan "la parte del león" de la oferta alojativa. Obviamente, esto puede tener que ver también con los cambios en los mercados, que demandarían cada vez más otro tipo de alojamientos y que harían más eficientes determinados tipos de gestión de la oferta. En cualquier caso, no pretendemos dar una explicación definitiva sino poner de manifiesto la compleja interrelación entre fenómenos económicos, económicamente relevantes y económicamente condicionados.

El estudio de la planificación urbanística del turismo permite ver que el resultado de los envites viene determinado por las posiciones de los agentes, los tipos de capital que poseen y las tasas de conver- 
sión entre cada uno de estos. La forma que adoptará la "competencia económica" entre las empresas turísticas viene determinada pues por las regulaciones al respecto. Por otra parte, la propia planificación urbanística se convierte en sí en un terreno para lo que podíamos denominar "competencia económica". Así por ejemplo, la competencia entre comerciantes no se limita sólo a la competencia en el mercado, sino que se da previamente como una lucha para facilitar o impedir la instalación de comerciantes: "si en la repetida Parcela " $X$ " se establecen locales comerciales, ello desembocaría en la más absoluta saturación de la zona; estadísticamente es inviable tal pretensión, pues la realidad está ahí, el Centro Comercial "XXX" tiene un 20\% de locales desocupados ${ }^{13}$ ". De la misma forma, ante la pretensión de instalación de un nuevo hotel en la zona, los hoteles existentes presentan alegaciones para impedirla, aludiendo a la saturación del mercado. Por supuesto, quienes pretenden justificarla aluden también a necesidades no cubiertas por el mercado. En definitiva, la idea es que la competencia hace continua referencia a las demandas del mercado, pero se basa en un mecanismo que no es de mercado.

Por último, algunas consideraciones acerca de los distintos tipos de capital que intervienen en el proceso de urbanización turística. Es necesario, obviamente, el capital económico, requisito para adquirir los terrenos y construir las infraestructuras. Pero además del capital cultural, son especialmente relevantes en este campo el capital social y el capital simbólico. No es ninguna novedad afirmar que disponer de relaciones es importante para poder llevar a cabo una urbanización turística, contando con el beneplácito de todas las administraciones implicadas. Lo que resulta más novedoso es plantear las relaciones como un tipo de capital, aunque pueda ser difícil de analizar. El capital social ha jugado sin duda un papel clave en el proceso de urbanización de Maspalomas. En el proceso de urbanización intervienen distintos agentes: promotores, constructores, propietarios del suelo, arquitectos que elaboran los planes parciales, ingenieros que evalúan impactos ambientales, abogados que presentan alega- ciones, etc. , según se desprende de de los documentos de planeamiento que constan en el archivo de la Dirección General de Política Territorial, en el momento en que se produce la urbanización muchos de los agentes implicados tienen el domicilio social en un mismo edificio de Las Palmas de Gran Canaria. Es decir, que si bien se trata de un edificio lo suficientemente grande como para acoger a distintas empresas, tanto el promotor, como el constructor o los abogados tienen la sede en el mismo edificio.

En cuanto al capital simbólico, resulta cada vez más importante, a medida que el desarrollo turístico va siendo mayor $\mathrm{y}$ más contestado. El capital simbólico tiene que ver con los imaginarios y valoraciones asociados a determinados espacios, instituciones y procesos sociales. Por ejemplo, en un contexto en que es altamente valorada por los ciudadanos podría decirse que la Iglesia posee un importante capital simbólico. En este sentido, en un contexto en que el desarrollo es un proceso social con un importante capital simbólico para los ciudadanos de las localidades que se desarrollan turísticamente, la asociación de ideas turismo $=$ desarrollo es un im ${ }^{-}$ portante capital social a favor de quienes promueven el desarrollo. Otras ideas, como "turismo de calidad = desarrollo" irían en la misma línea. Por el contrario, la oposición de colectivos ecologistas a desarrollos urbanísticos va ganando fuerza en la medida en que las sociedades "turísticas" van otorgando cada vez un mayor capital simbólico a espacios naturales que quizá anteriormente estaban desprovistos de los mismos. Un ejemplo de esto serían los movimientos populares contrarios a la urbanización de Veneguera, en el municipio de Mogán. Mientras unos agentes intentan llevar el envite al terreno de lo económico ("turismo es progreso") otros se niegan a ello, al considerar que existen espacios que no son susceptibles de valoración en términos de productividad. La novedad estriba en que el planteamiento del "capital simbólico" implica que se trata de algo que se puede acumular, traspasar, incrementar o perder, y que se pueden llevar a cabo estrategias, conscientes o no, al respecto. Los principales promotores y constructores 
del Sur de Gran Canaria (que a partir de los noventa se convierten también en hoteleros) entran a partir de la segunda mitad de los noventa en el accionariado de los equipos representativos de la isla en baloncesto y fútbol, tras un cambio en la normativa deportiva. Aunque estas acciones han tenido malos resultados económicos pueden ser vistas como una inversión en capital simbólico.

El análisis de los modelos productivos en turismo a partir de una perspectiva que intente integrar la Economía con otras Ciencias Sociales permite contemplar los modelos de desarrollo turísticos no como el resultado de "imperativos universales" de la economía sino como el resultado de la interacción de sujetos intencionales. La idea de que los modelos productivos son el resultado de la interacción entre mecanismos de mercado, que podríamos estudiar con los instrumentos de la economía al uso, y mecanismos institucionales y de regulación, que se comprenden mejor desde otras Ciencias Sociales, está relativamente asentada en otros campos productivos distintos al turismo. Boyer y Freyssenet (2001) la han aplicado al sector automovilístico, a partir de la aportación inicial de Piore y Sabel (1990). Sin embargo, en turismo sigue existiendo una tendencia a presentar determinados modelos de organización que en un momento concreto alcanza el éxito como la única forma "competitiva" de organizar el sector. Y por tanto, a las comunidades que disfrutan o padecen el desarrollo turístico no les quedaría otra solución que adaptarse a los requerimientos del mercado.

\section{Conclusiones}

El estudio de la planificación urbanística como fenómeno "económicamente relevante" previo al desarrollo turístico y concretamente el caso de Maspalomas que se ha analizado permiten extraer algunas conclusiones que pueden ser útiles para el análisis de la actividad económica turística desde una perspectiva más amplia que la tradicionalmente contemplada, Si retomamos la tipología del capitalismo propuesta por Weber que vimos al principio (capitalismo comercial tradicio- nal, capitalismo político, capitalismo racional) resulta muy difícil, tras realizar este análisis, no relacionar la economía del turismo con el "capitalismo político", ya que parte de las ganancias van sin duda asociadas a sistemas de regulación política. Tradicionalmente la "economía del turismo" ha sido visita con cierto desdén como una "economía especulativa", "economía rentista", etc., bajo el supuesto implícito de que sólo una economía "productiva" promueve a medio y largo plazo el desarrollo de las comunidades. Después de cuarenta años de desarrollo turístico, si bien sigue siendo tentador ver al turismo como una economía basada en el "capitalismo político", siguiendo la terminología de Weber, parece necesario revisar la idea de que un desarrollo económico basado en este tipo de factores es una especie de bluff que ha de pinchar a medio plazo, pues el medio plazo parece haber ya transcurrido. Quizá es más interesante considerar los conceptos de "actividades económicas, económicamente orientadas y con consecuencias económicas" como polos de un mismo continuo donde las fronteras nunca son del todo precisas. La idea de Bergson de que "se requieren siglos de cultura para producir un utilitarista como Stuart Mill" (citado en Bourdieu, 2003) nos llevaría a ser más humildes acerca de lo que son nuestras concepciones de la economía o lo económico.

Si la idea de "lo económico" puede cambiar a lo largo del tiempo, el estudio de la planificación urbanística para el caso de Maspalomas ha permitido ver que "los buenos resultados económicos" pueden definirse de manera distinta a lo largo del tiempo, pasando de "incrementar la renta" a "incrementar la productividad". Podría plantearse como hipótesis que en función de la fase del ciclo de vida del área turística en que se encuentre un destino (Butler, 1980) es más plausible que los poderes públicos definan la economía en unos $\mathrm{u}$ otros términos. La manera en que esto se ha llevado a cabo en el caso de Maspalomas ha implicado pasar de una primera fases del desarrollo turístico que permitieron el acceso de numerosos pequeños capitalistas locales a la actividad a una segunda fase en que los 
grandes capitalistas (locales o no) mejoran sus posiciones y se favorece la aparición de situaciones de oligopolio. Del análisis del caso de Maspalomas se podría desprender la idea de que situaciones similares podrían darse cuando convive una inicial escasez de capital local dispuesto a invertir en la actividad turística con regímenes políticos relativamente autárquicos. El urbanismo, como plasmación física del equilibrio de poderes en una sociedad, permitiría adivinar que modelos turísticos como los de Benidorm o Lloret de Mar, basados en la construcción en vertical y modelos como el de Maspalomas, y en general el resto de Canarias, con mayor importancia de la construcción en horizontal, obedecen a equilibrios sociales distintos.

En cuanto a las consecuencias que un enfoque de este tipo puede tener para el análisis y la gestión de los destinos turísticos, es importante comprender que distintos modelos turísticos pueden obedecer a distintos planteamientos de lo que se considera "el objetivo de la economía". Así por ejemplo, un modelo basado en el "turismo sostenible" (cualquiera que sea el significado que se le dé a este término) debería definirse en base al incremento de la productividad y no de la renta total generada en un territorio. Esto quiere decir que, en función de cómo se reparta socialmente la riqueza, algunos agentes económicos pueden considerar que el incremento de la renta es insuficiente para sus expectativas, y presionar por tanto para un crecimiento turístico a mayor escala. No hay que olvidar que la opción por uno u otro tipo de "modelo turístico" mediante mecanismos como los costes de entrada favorece a unos y perjudica a otros. La opción por uno u otro no debería pues tomarse sólo en base a argumentos supuestamente técnico- urbanísticos, ni en base a consideraciones "económicas" consideradas como meramente técnicas. La opción ha de tener en cuenta también factores sociales, y es por ello necesario, en la línea de lo que señalaba Sapir (2004), recuperar para la discusión política cuestiones que en ocasiones se relegan a una discusión económica concebida co- $^{-}$ mo sinónimo de "técnica".

\section{Bibliografía}

Bianchi, Raoul.

2002 "Towards a New Political Economy of Global Tourism" en Sharpley, Richard y Telfer, David (Eds): Tourism and Development. Concepts and Issues, Clevedon: Channel View.

Bourdieu, Pierre.

1994 La distinción. Criterio y bases sociales del gusto, Madrid, Akal.

2000 Cuestiones de Sociología, Madrid, Itsmo.

2003 Las estructuras sociales de la economía, Barcelona, Anagrama.

Boyer, Robert y Freyssenet, Michel.

2001 El mundo que cambió la máquina, en Sociología del Trabajo, 41.

Butler, R.

1980 The concept of a Tourist Area Cycle of Evolution: Implications for Management of Resources, en Canadian Geographer24 (1):5 -12.

Davies, Brian.

1999 Industrial Organization: The UK Hotel Sector, en Annals of Tourism Research 26 (2):294-311.

Donaire, José, Fraguell, Rosa y Mundet, Lluis.

1997 La Costa Brava ante los nuevos retos del turismo, en Estudios Turísticos, 133:77-96.

Gobierno de Canarias

2001 Directrices de Ordenación General y del turismo de Canarias: avance. Libro II: de las directrices de ordenación del turismo. Las Palmas de Gran Canaria, Consejería de Política Territorial y Medio Ambiente, Gobierno de Canarias.

2002 Directrices de Ordenación del turismo de Canarias. Las Palmas de Gran Canaria, Consejería de Política Territorial y Medio Ambiente, Gobierno de Canarias.

2006 Estadística de Plazas Hoteleras y Extrahoteleras. Las Palmas de Gran Canaria, Consejería de Turismo, Dirección General de Ordenación y Promoción, Disponible en internet en http://www.gobiernodecanarias.org/tur ismo/estad/plazas/plazas/plazas.htm

Ioannides, Dimitri y Debbage, Keith

1997 Post- Fordism and flexibility: the travel industry polyglot, en Tourism 
Managment 18 (4);229-241.

Jafari, Jafar.

$2005 \mathrm{El}$ turismo como disciplina científica en Política y Sociedad, 42 (1):39-56.

Marchena Gómez, Manuel.

1994 Un ejercicio prospectivo: de la industria del turismo "fordista" al ocio de producción flexible, en Papers de Turisme.

Mazón, Tomás.

2001 El modelo turístico fordista y el postfordista en Mazón, Tomás: Sociología del Turismo, Madrid: Centro de Estudios Ramón Areces.

Piore, Michel J. y Sabel, Charles.

1990 La segunda ruptura industrial, Madrid: Alianza Universidad.

Ritzer, George.

1993 Teoría Sociológica contemporánea, Madrid: Mac Graw-Hill.

Samuelson, Paul A. y Nordhaus, William D.

1999 Economía, MacGraw-Hill:Madrid (13 Edición)

Santana Turégano, Manuel Ángel.

2000 "Turismo fordista y postfordista.

Una primera aproximación a la operativización de conceptos" en Latiesa Rodríguez, Margarita, y Álvarez Sousa, A (ed): El turismo en la sociedad contemporánea: diversificación, competitividad y desarrollo, Editorial Urbano: Granada.

2001 Impacto de la actividad turística sobre el uso del territorio y las actividades económicas tradicionales en $\mathrm{Ca}^{-}$ narias. Un estudio de casos en Maspalomas (Gran Canaria), Memoria de la Beca de Investigación sobre Turismo y Territorio, Lanzarote: Fundación César Manrique (inédito)

2003 Formas de desarollo turístico, redes y situación de empleo. El caso de Maspalomas (Gran Canaria). Tesis Doctoral, Universidad Autónoma de Barcelona. Barcelona, Consorci Interuniversitari de Catalunya, disponible en internet: http://www.tdx.cesca.es/TDX0123104-173733/

Sapir, Jaques.

2004 Economistas contra la democracia: los intereses inconfesables de los falsos expertos de la economía Barcelona: Ediciones B.
Savelli, Asterio.

1990 Innovación y desarrollo de las empresas turísticas pequeñas y medianas, en Sociología del Trabajo, 10:2540.

Swedberg, Richard y Granovetter, Mark 2001 "Introduction to the Second Edition: The Sociology of Economic Life". en Swedberg, Richard y Granovetter, Mark (Eds), The Sociology of Economic Life, Cambridge MA: Westview Press. Tezanos, José F.

2001 La explicación Sociológica. Una introducción a la sociología. Madrid: UNED

\section{NOTAS}

\begin{abstract}
${ }^{1}$ Agradezco a los compañeros y compañeras de la Universidad de La Laguna, especialmente a Raúl Hernández Martín, las conversaciones que me han ayudado a avanzar en este texto. Por supuesto, la responsabilidad de lo que aquí se dice es
\end{abstract} sólo mía.

2 Se utiliza el término envite, juego de cartas típico en Canarias, como traducción del enjeu que utiliza Bourdieu, que hace referencia tanto a $l o$ que está en juego (enjeu) en cada partida, es decir, el objetivo (quitarse todas las cartas de encima, obtener un palo completo, etc.) como al desafío, las reglas de juego o la partida (enjeu). Martín Criado traduce los enjeux en Bourdieu (2000) como objetivo, apuesta, o "lo que está en juego".

${ }^{3}$ Por ejemplo, el desarrollo turístico en las zonas del sur de las Islas Canarias se da en aquellas áreas que tradicionalmente eran más atrasadas, y a las cuales las poblaciones locales no daban ningún valor ya que la elevada insolación y aridez las hacía poco productivas desde un punto de vista agrícola. Para que se desarrollaran turísticamente fue preciso un "emprendedor" que a modo de "mediador intercultural" comprendiera precisamente las características que le quitaban valor a las tierras desde el punto de vista agrícola las hacían muy productivas en un contexto de turismo de sol y playa.

${ }^{4}$ Los cambios en la nomenclatura tienen que ver con los cambios legislativos que han tenido lugar.

5 Para más detalle, véase Santana Turégano, 2001.

${ }^{6}$ Extraído del archivo de la Dirección General de Planeamiento- Islas Orientales, Consejería de Política Territorial y Medio Ambiente, Edificio de Servicios 
Múltiples II, Plaza de los Derechos Humanos s/n, Las Palmas de Gran Canária

${ }^{7}$ Alegación presentada por particular el 21 de enero de 1986 a las Normas Subsidiarias de San Bartolomé de Tirajana. De 1986 Extraído del archivo de la Dirección General de Planeamiento- Islas Orientales, Consejería de Política Territorial y Medio Ambiente, Edificio de Servicios Múltiples II, Plaza de los Derechos Humanos s/n, Las Palmas de Gran Canaria.

${ }^{8}$ Alegación realizada por grupo hotelero el 2001-1986.

9 Alegación presentada por particular el 23-011986.

${ }^{10}$ Alegación por el 20-01-1986 presentada importante compañía constructora, que en la actualidad ha diversificado su actividad hacia el sector hotelero, comercial y de comunicaciones.

${ }^{11}$ Concejal de Turismo y Urbanismo de San Bartolomé de Tirajana, en entrevista publicada en Diario de Las Palmas, Lunes 4 de Agosto de 1997, p 83.

${ }^{12}$ Por el momento en que éstas se dieron (hasta la mitad de los años ochenta del siglo XX), pensamos que éstas no deben entenderse como un intento de reorientar la oferta turística hacia un modelo de calidad en que el incremento de la productivdad no se diera por vía del volumen sino de la calidad.

${ }^{13}$ Alegación presentada en abril de 1985 por la Comunidad de Propietarios de un Centro Comercial a las Normas Subsidiarias del municipio, que planteaban (y finalmente así se hizo) la instauración de un centro comercial en sus proximidades.

Recibido:

07 de abril de 2006

Reenviado: 20 de octubre de 2006

Aceptado: 18 de noviembre de 2006 Sometido a evaluación por pares anónimos 